\title{
МЕДИАИССЛЕДОВАНИЯ MEDIA STUDIES
}

DOI 10.17150/2308-6203.2020.9(3).443-461
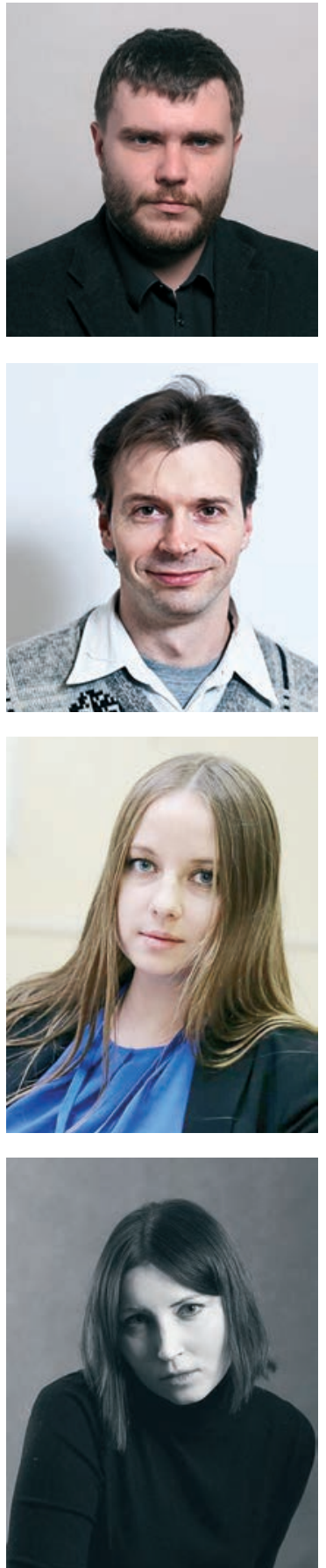

\section{Вырковский Андрей Владимирович}

Доктор филологических наук, доцент

Кафедра теории и экономики СМИ фракультета

журналистики, Московский государственный университет

им. М.В. Ломоносова, г. Москва, e-mail: a.v.vyrkovsky@gmail.com

\section{Anrdey V. Vyrkovsky}

D.Sc. in Philology, Associate Professor

Department of Media Theory and Economics, Faculty of Journalism, Lomonosov Moscow State University, Moscow, e-mail: a.v.vyrkovsky@gmail.com

\section{Колесниченко Александр Васильевич}

Кандидат фрилологических наук, доцент

Кафедра периодической печати фракультета журналистики Московский государственный университет

им. М.В.Ломоносова, г. Москва, e-mail:april-7@yandex.ru

\section{Aleksandr V. Kolesnichenko}

PhD in Philology, Associate Professor

Department of Periodical Press, Faculty of Journalism,

Lomonosov Moscow State University, Moscow,

e-mail: april-7@yandex.ru

\section{Образцова Анастасия Юрьевна}

Научный сотрудник

Проблемная научно-исследовательская лаборатория комплексного изучения актуальных проблем журналистики фракультета журналистики, Московский государственный университет им. М.В. Ломоносова, г. Москва e-mail: obraztsova.anastasia@gmail.com

\section{Anastasia Yu. Obraztsova}

Research Fellow

Basic Research Laboratory of Integrated Study of Current Issues of Journalism, Faculty of Journalism, Lomonosov Moscow State University, Moscow, e-mail: obraztsova.anastasia@gmail.com

\section{Галкина Марина Юрьевна}

Кандидат фрилологических наук, научный сотрудник Проблемная научно-исследовательская лаборатория комплексного изучения актуальных проблем журналистики фракультета журналистики, Московский государственный университет им. М.В. Ломоносова, г. Москва e-mail: marina.galkina@mail.ru

\section{Marina Yu. Galkina}

$\mathrm{PhD}$ in Philology, Research Fellow

Basic Research Laboratory of Integrated Study of Current Issues of Journalism, Faculty of Journalism, Lomonosov Moscow State University, Moscow, e-mail: galkina@mail.ru 

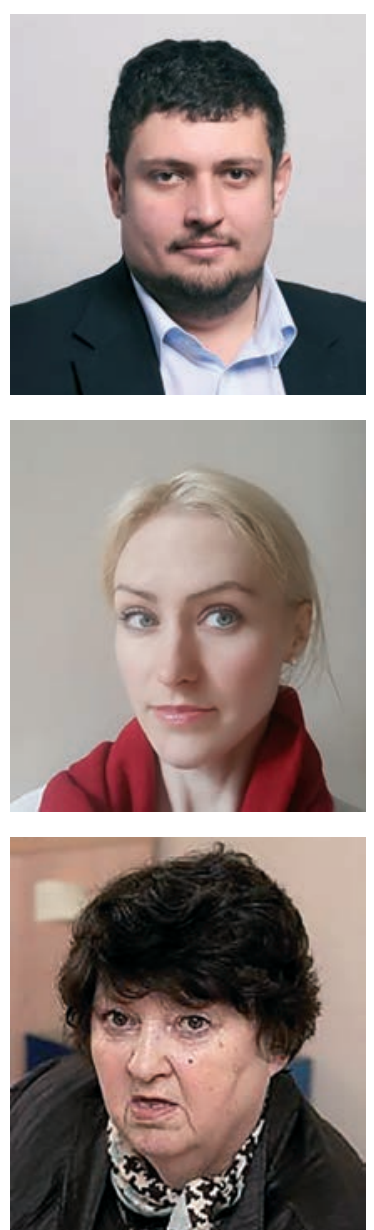

\section{Смирнов Сергей Сергеевич}

Кандидат фрилологических наук, доцент

Кафедра теории и экономики СМИ факультета

журналистики, Московский государственный университет

им. М.В. Ломоносова, г. Москва, e-mail: smirnov_s@rambler.ru

\section{Sergey S. Smirnov}

$\mathrm{PhD}$ in Philology, Associate Professor

Department of Media Theory and Economics, Faculty of Journalism, Lomonosov Moscow State University, Moscow, e-mail: smirnov_s@rambler.ru

\section{Владимирова Мария Борисовна}

Кандидат фрилологических наук, доцент

Кафедра теории и экономики СМИ фракультета

журналистики, Московский государственный университет

им. М.В. Ломоносова, г. Москва, e-mail: tvmar2006@mail.ru

Maria B. Vladimirova

$\mathrm{PhD}$ in Philology, Associate Professor

Department of Media Theory and Economics, Faculty of Journalism, Lomonosov Moscow State University, Moscow, e-mail: tvmar2006@mail.ru

\section{Фомичева Ирина Дмитриевна}

Доктор филологических наук, профессор

Факультет журналистики, Московский государственный университет им. М.В. Ломоносова, г. Москва, e-mail: fomichira@gmail.com

Irina D. Fomichyova

D.Sc. in Philology, Professor

Department of Sociology of Mass Communications, Faculty of Journalism, Lomonosov Moscow State University, Moscow, e-mail: fomichira@gmail.com

\section{ТРАНСФОРМАЦИЯ РАБОТЫ СОТРУДНИКОВ ИНФОРМАЦИОННЫХ РАДИОСТАНЦИЙ В УСЛОВИЯХ ЦИФРОВИЗАЦИИ}

Аннотация. Интервью с топ-менеджерами российских информационных радиостанций показали, что цифровизация оказала серьезное влияние практически на все аспекты работы сотрудника новостной радиостанции: от поиска информации и требований к профессиональным компетенциям до организационной структуры редакции.

Радио в Интернете набирает обороты, аудитория массово использует доступ к станциям через гаджеты и иные цифровые платформы.

Медиаменеджеры не сошлись во мнении о влиянии цифровизации на экономику радиостанций. С одной стороны - минимизация издержек (к примеру, облачные ресурсы позволили сократить расходы на хранение данных), с другой - новые статьи расходов (запуски новых фрорматов, приложений, привлечение новых специалистов по работе с контентом). К тому же, с этим связано самое главное изменение в структуре редакции - появление технических подразделений, отвечающих за различные аспекты работы над сайтом. 
Большинство медиаменеджеров отметили, что набор необходимых компетенций работника новостной радиоредакции увеличился. Радиожурналист обязан в большинстве случаев продвигать свой материал в социальных сетях. Коммуникация с коллегами в мессенджерах практически заменила живое общение: общение в них заменяет телефонные звонки и переписку по электронной почте.

Однако некоторые аспекты функционирования информационных радиостанций в условиях цифровизации остались прежними - использование FM-диапазона выгодно всем участникам рынка (так как затраты при переходе на новые форматы невыгодны как вещателям, так потребителям).

Ключевые слова. Конвергенция, структура редакции радио, коммуникация с ньюсмейкерами, поиск информации, навыки журналиста

Вклад авторов. Вырковский Андрей Владимирович - руководство проектом, разработка стратегии исследования, экспертиза методик, проведение полевых исследований.

Образцова Анастасия Юрьевна - со-руководство проектом, разработка стратегии исследования, экспертиза методик, проведение полевых исследований, обработка результатов исследования, написание текста рукописи.

Колесниченко Александр Васильевич - разработка стратегии исследования, экспертиза методик, проведение полевых исследований

Галкина Марина Юрьевна - экспертиза методик, проведение полевых исследований.

Смирнов Сергей Сергеевич - разработка стратегии исследования, экспертиза методик, проведение полевых исследований.

Владимирова Мария Борисовна - проведение полевых исследований

Фомичева Ирина Дмитриевна - со-руководство проектом, разработка стратегии исследования.

Финансирование. Статья выполнена в рамках исследовательского межкафедрального проекта «Структура работы российского радиожурналиста в цифровой среде», проводимого сотрудниками фракультета журналистики МГУ имени М.В. Ломоносова в 2018-2019 гг.

Информация о статье. Дата поступления 28 мая 2020 г.; дата принятия к печати 25 сентября 2020 г.; дата онлайн-размещения 30 сентября 2020 г.

\section{CHANGES IN NEWS RADIO EDITORS' WORK IN THE CONTEXT OF DIGITALIZATION}

\footnotetext{
Abstract. The aim of this research is to study the impact ща the new technologies on the contemporary news radiobroadcasting.

The research methods include a half-structured interview with top managers of Russian news radio stations. The interview showed that digitalization has had a significant influence on almost all aspects of work of the news radio, from searching for information to professional requirements for the staff and the organization structure of the radio's editorial board.

Having analyzed the results of the interview, the authors have made the following inferences.

The number of the competences the personnel of a news radio station is to possess has increased. The technological development has led to multitasking in the work of the personnel of a news radio: via the computer and mobile devices, they have to combine searching for information and working
} 
on the text with looking through and texting messages, and promoting their content in social networks. Due to its usability and operational efficiency, communication via messengers has almost replaced personal communication, telephone conversations and e-mail writing.

As for the effect of digitalization on the economic aspect of radio stations' activity, it has been ambivalent. On the one hand, it has helped radio stations to minimize expenses on data storage, thanks to the cloud services. On the other hand, the work on the new formats, launch of new applications and hiring content managers have required other expenses. The most common change in the structure of a typical radio editorial board is the emergence of IT departments.

However, some aspects of work of news radio stations have remained unchanged despite digitalization. For instance, the use of FM-band is still popular with the market participants, who are not ready for expenses on transition to a new format.

Keywords. Convergence, structure of a radio editorial board, communication with newsmakers, information retrieval, journalists' practical skills.

Contributorship. Anrdey V. Vyrkovsky - project management, development of research strategy, expertise of research methods, carrying out field studies.

Anastasia Yu. Obraztsova - project management, development of research strategy, expertise of research methods, carrying out field studies, elaboration, text writing.

Aleksandr V. Kolesnichenko - development of research strategy, expertise of research methods, carrying out field studies. studies.

Marina Yu. Galkina - expertise of research methods, carrying out field

Sergey S. Smirnov - development of research strategy, expertise of research methods, carrying out field studies.

Maria B. Vladimirova - carrying out field studies.

Irina D. Fomichyova — project management, development of research strategy.

Funding. The work has been completed within the frames of the interdepartmental project titled "The structure of Russian journalist's work in the digitlal environment" carried out by the Faculty of Journalism of Lomonosov MSU in 2018-2019.

Article info. Received May 28, 2020; accepted September 25, 2020; available online September 30, 2020.

\section{Теория и литература}

Изменения, которые можно назвать радикальными, происходят в российской радиоиндустрии из-за развития социальных сетей, новых площадок для работы с аудиторией, трансформации национального медиарынка и нарастающей конкуренции разных типов СМИ. Несомненно, медиапредприятия вынуждены реагировать на эти фракторы, вы- рабатывать новые стратегии работы с информацией, менять процесс управления персоналом редакции.

Исследования особенностей внедрения конвергентных практик в процесс создания журналистского материала периодически проводились в зарубежных странах. Существует корпус работ, которые описывают трансформации деятельности структур и организационных культур [1-4]. 
Большинство публикаций рассматривают управление медиа как социально-значимый процесс, эффрективность которого должна быть оценена не только в контексте доходов. Многих западных исследователей интересуют изменения в управлении медиакомпаниями в условиях изменения медиаландшафта вследствие влияния новых технологий и динамики конкурентной среды [5-11]. Большое количество работ посвящено системной трансформации медиаотрасли [12-16]. Среди концептуальных трудов, посвященных современному состоянию индустрии, можно выделить коллективную монографиюю Е.Л. Вартановой, А.В. Вырковского, М.И. Макеенко, С.С. Смирнова [17].

Работы А.В. Вырковского [18; 19], С. Дал Зотто [20], К.С. Киллебрева [21], М.К. Лунда [22] посвящены вопросам трансформации деятельности редакций в условиях новой конвергентной среды.

Большая часть научных публикаций посвящена развитию классических СМИ во «всемирной паутине».

Л. Кюнг [23] считает, что усиление конкуренции на рынке оказывает сильное давление на медиаменеджеров разного уровня, заставляя их постоянно вносить изменения в управление редакцией и стратегию создания продукта для сохранения баланса доходов и расходов. Р. Пикар [24], Дж. Оливер [25; 26] рассматривают в своих работах типы стратегий медиаорганизаций и применяемых для их изменений аналитических инструментов, которые часто используются для организационной политики и принятия управленческих решений. Выживанию СМИ в цифровой среде посвящено и проведенное в 2017 г. компанией Mail.ru исследование «Интернет-журналистика: адаптация к меняющейся реальности» [27], включающее в себя 28 интервью с руководителями интернет-проектов.

Внедрение новых технологий изменило рабочие процессы, в том числе и производство новостей - сбор инфрормации, создание и распространение инфрормационного продукта. Если раньше радиожурналистов учили писать «для уха», использовать «разговорный язык» и «рисовать картины» [28], то сегодня большее внимание уделяется другим процессам. Журналистам предлагают предоставлять больше информации в связи с оптимизацией - уменьшением числа сотрудников в штате.

Задача данного исследования выяснить, каким образом новые технологии оказали влияние на современное информационное радиовещание: что изменилось в формах и особенностях подачи информации на современных российских новостных радиостанциях, каким образом адаптируется работа (и есть ли изменения в принципе?) радиожурналиста и редактора к условиям меняющейся реальности, какие изменения произошли на уровне управления персоналом, т.е. как в радиоредакции управляют трудом и продуктами творческой деятельности журналиста.

\section{Методология}

Гипотеза нашего исследования заключалась в том, что новые технологии вызвали кардинальные изменения в рабочем процессе современного российского радиожурналиста: начиная от поиска темы, сбора информации, коммуникации с ньюсмейкерами, коллегами и начальством до создания конечного журналистского 
продукта. При этом трансформации также подверглись организационная структура редакции, стиль руководства и оценки эффективности работы радиожурналиста.

Исследование проводилось в ноябре и декабре 2018 г. методом полуструктурированного интервью. Именно методика качественного исследования с ведущими представителями новостных радиостанций стали ключевым инструментарием полевого этапа исследования. Мы опрашивали только топ-менеджеров первого и второго уровней (главный редактор, генеральный директор, глава подразделения, их заместители) с опытом работы не менее 10 лет. Данное ограничение было необходимо, поскольку: а) респондент мог сравнить нынешние рабочие процессы с теми, которые были в конце девяностых - начале двухтысячных годов; б) требовалось понять, какие изменения произошли в стратегии управления российской новостной радиоредакцией, а стратегические решения принимаются на перечисленных уровнях менеджмента.

Критерием отбора новостных радиостанций для исследования стало существование собственной службы новостей, а также присутствие новостных программ в эфире. Поэтому мы сознательно исключили из фокуса нашего научного интереса «Детское радио», так как его невозможно отнести к классическим радиостанциям формата All News/News \& Talk из-за специфики тематического наполнения и особенностей формирования программной сетки в соответствии с интересами целевой аудитории. Кроме того, на станции отсутствует новостная бригада.
На этом этапе исследования мы взяли федеральные и московские радиостанции, так как в регионах мало оригинальных новостных станций, и информации о них не хватает. К тому же, региональные новостные станции практически не сопоставимы по охвату с московскими. Всего было проведено 10 интервью с представителями следующих российских новостных радиостанций: «Коммерсантъ FM» (P2), Business FM (Р3), «Радио России» (Р4), «Серебряный дождь» (P5), «Комсомольская правда» (Р6), «Звезда» (P7), «Говорит Москва» (Р8), «МИР» (Р9), «Эхо Москвы» (Р10). Кроме того, мы взяли интервью у топ-менеджера российской станции Sputnik (P1), вещающей на зарубежные страны, которая также укомплектована преимущественно российскими сотрудниками и потенциально может работать в рамках редакционной культуры, схожей с существующей в отечественных реалиях.

Отметим, что за время нашего исследования произошла трансформация в сфрере новостного вещания: изменила фрормат вещания радиостанция «Свобода», отказавшись от эфирного вещания, прекратила вещание на территории Российской Федерации радиостанция «Голос Америки».

Представленная выборка дает возможность отразить качественные изменения в рабочем процессе новостной радиоредакции, однако не позволяет точно определить количественные закономерности. Полуструктурированные интервью с представителями девяти российских новостных радиостанций показали, что процесс цифровизации оказал сильное влияние на российскую 
радиоиндустрию на трех уровнях: 1) индустрия в целом, 2) редакция, 3) сотрудники.

\section{Результаты}

\section{РАДИОИНДУСТРИЯ}

\section{Цифровизация и рынок радио}

Большинство опрошенных руководителей информационных радиостанций считают, что внедрение новых технологий идет на пользу радиовещанию. Технологический прогресс расширил возможности радио, которое, для того чтобы быть успешным в конкурентной среде, стремится подстроиться под новую реальность. Респонденты в целом признают, что радио развивается, используя цифровые площадки и охватывая аудиторию самыми разными способами: у всех в студиях стоят камеры, все вещают видео в Интернет, все активно используют социальные сети.

На сегодняшний день, как говорят многие респонденты, привычное потребление радиоконтента (включил приемник и слушаешь радио) ушло в прошлое. Информационные радиостанции должны не просто подстраиваться под новые модели медиапотребления, но и обращать их в свою пользу: не просто дублировать вещание в Интернете, а делать подкасты, мобильные приложения. По мнению одного из респондентов (P2), за последний год прослушивание радио в автомобилях, на домашних приемниках, в Интернете через компьютер уменьшилось, зато через портативный плейер или другое мобильное устройство - увеличилось.

$$
\text { Однако некоторые топ- }
$$
менеджеры считают, что не все игроки рынка готовы к освоению новых технологий в силу укоренившейся привычки к производству определенного вида контента и изза нехватки специалистов. Один из респондентов (P5) заявил, что требуется менять собственную психологию, а также привлекать огромное количество специалистов, для того чтобы работа радиостанций приобретала гибкие формы: радио должно расширять свои платформы и каналы распространения, быть не только FM, но быть и подкастами, быть Youtube, быть социальными сетями.

\section{Конкуренция. Развитие цифровых платформ. Переход на форматы DAB и DRM}

B ближайшее время эфирное радиовещание, в частности, сегмент информационно-разговорных форматов, останется аналоговым. Использование FM-диапазона выгодно всем участникам рынка. Именно поэтому некоторые респонденты считают, что на рынке присутствует элемент «искусственного сдерживания развития цифровых платформ» и даже называют ситуацию кризисной. Однако, по мнению большинства респондентов, традиционные радиостанции опасаются, что не выдержат конкуренции со стороны новичков. Как сказал один из респондентов (P1), «запуск, например, DAB и DRM выведет на рынок несколько сотен радиостанций новых. И если сейчас в Москве 50 радиостанций, а будет, допустим, 250, понятное дело, что люди пойдут на что-то новенькое и им будет что-то интересно другое».

Проникновение в цифровые среды и распространение там контента имеет еще и экономическую составляющую, отмечают эксперты. Для 
того чтобы чувствовать себя уверенно в среде, где конкурируют не три десятка радиостанций, находящихся в одном диапазоне, а сотни тысяч игроков, сходных по параметрам, требуются инвестиции, которые есть далеко не у всех. Респонденты сходятся во мнении (P7), что на рынке останутся только сильные игроки: недостаток инвестиций рано или поздно приведет к тому, что, скорее всего, количество информационных радиостанций уменьшится.

Впрочем, большинство опрошенных респондентов полагает, что конкуренция в сфере информационного вещания останется на прежнем уровне. Например, один из респондентов (P3) характеризует московский рынок $F M$-вещания как один из самых конкурентных в мире, потому что «в Москве не меньше радиостанций, чем в Нью-Йорке, и гораздо больше, чем в Париже или в Лондоне. В Англии власти и связь ограничивают число выдаваемых лицензий, в России нет. Ограничения связаны только с фризической возможностью эфира пропускать...». Он поясняет, что количество денег в Москве и НьюЙорке сильно отличается («в Москве денег меньше во много-много-много раз, чем в Нью-Йорке, а количество радиостанций такое же»), поэтому «борьба за каждую тысячу рублей, за каждый миллион рублей очень жесткая и такая кровавая» (Р3).

Специалисты скептически относятся к появлению возможных конкурентов при переходе на цифру именно в среде информационного вещания (форматы All News, News \& Talk). Но дело даже не в боязни соперничества со стороны новых (возможных) игроков радиорынка. Одна из ключевых проблем, по мнению опрошенных топ-менеджеров, - это стоимость перехода на новые стандарты. Помимо возможных затрат, которые понесут вещатели, самим потребителям придется тратить собственные в средства на покупку радиоприемников нового образца. А переход на цифровые платформы предполагает огромные затраты поясняет респондент (Р3). Он говорит, что сегодня получить право на вещание в эфире, право на аналоговую частоту связано с очень сложной разрешительной процедурой, с большими затратами: только для того, чтобы участвовать в конкурсе на право вещания, нужно заплатить несколько миллионов рублей, а еще нужны приемники у потребителя, специальное оборудование у производителя контента. И проблема заключается в том, как заставить потребителя покупать приемники. Респондент также отмечает, что индустрия не готова за это платить («просто нет таких денег»), а «государству это тоже как-то не особо нужно и оно не собирается это фиинансировать, в отличие от телевидения - разные масштабы аудитории, не такое электоральное значение».

\section{Экономика}

Медиаменеджеры уверены, что влияние цифровизации на экономику радиовещания двояко. Несомненно, она позволяет минимизировать некоторые издержки. В частности, развитие системы хранения данных сократило затраты на архив. Эксперты также отмечают удешевление производства контента и систем хранения: «современные системы хранения позволяют нам хранить то, что мы производим, и удобно извлекать, если я поинтересуюсь - a 
о чем мы говорили, допустим, 6 декабря 2011 г. И я это довольно легко и скоро могу получить» (Р3); «производство продукта удешевилось точно. Особенно создание облачных ресурсов. Это удобно, не надо жестких дисков никаких» (P9). Некоторые респонденты говорят, что цифровизация благотворно повлияла на радио: технологии полностью преобразовали весь процесс производства программ, в том числе удешевили затрат в самых разных областях например, больше нет необходимости содержать дорогостоящие помещения, люди не обязательно должны находиться в одном месте» (P7). К тому же, цифровизация расширяет рекламный потенциал радиостанций, возможность создавать новые форматы, а также более точно определять целевую аудиторию (ее состав, социальные и экономические статусы), взаимодействовать с региональными радиостанциями, где есть локальные вставки (Р3).

Однако часть опрошенных считает, что вместе с новыми технологиями пришли новые статьи расходов (по мнению некоторых экспертов, колоссальные): запуски новых форматов, которые востребованы в сети, в том числе в социальных сетях, а также новых приложений, размещение подкастов на разных площадках (SMM), привлечение дорогих специалистов.

Впрочем, цифровизация уже сегодня оказывает положительное влияние на доходность радиостанций. Один из топ-менеджеров (P2) делает вывод, что доходы выросли: «раньше платили за проекты или партнерский контент только в эфире, сейчас все хотят также выкладку на сайте и в социальных сетях».
Топ-менеджеры сходятся во мнении, что в ближайшем будущем источников дохода станет больше (многие респонденты согласны, что вскоре мобильные приложения будут приносить неплохой доход), но пока что базовая модель - рекламная - останется основным источником прибыли. Так, один из респондентов (P4) убежден, что монетизация должна стать выше: будет больше «рекламного инвентаря», интернет-платформы расширят список рекламодателей.

\section{РЕДАКЦИЯ}

\section{Организационная структура редакции. Кадры}

Практически все медиаменеджеры указали на появление в радиоредакциях специалистов по работе с социальными сетями и SMM-менеджеров. Немногие респонденты рассказали о новых сотрудниках отделов, связанных с освоением цифровых платформ. Например, в одной радиоредакции появился новый заместитель по вопросам социальных сетей и Youtube, в другой - специальный отдел, который занимается тем, чтобы адаптировать этот контент, а также «подразделение в редакции, которое занимается исключительно социальными сетями» (Р10). Другие руководители настаивают, чтобы сотрудники сами продвигали свои материалы: «мы их обязываем выкладывать ссылки на свои материалы в социальных сетях, общаться со слушателями, отвечать на комментарии» (Р6). Один из респондентов отметил, что редакция делает акцент на интернет-площадки, поэтому штат «увеличился за последние 
годы человек на 10, чтобы обеспечить присутствие в Интернете» (Р2).

Социальные сети становятся едва ли не основным источником продвижения. Промоушн радиостанций строится по-разному: например, поддержание интереса во всех средах, когда интерактивность прямого эфира из студии поддерживается селфи, которое выкладывается в соцсеть (P9). Журналисты и авторы программ на радио также могут рассказать в социальных сетях о своей программе или сопроводить свой репортаж фротоматериалами и видео и выложить это на сайт, а также в соцсети (Р4).

Респондент (Р3) рассказал о новой роли журналиста, которого обычно называют «эфирным новостником»: «есть ребята, которые готовят новости и выходят с ними в эфир, между выпусками новостей, там 5-7 мин. перерыва, они пишут новости для сайта и публикуют. Это такое важное, большое достижение. Тоже было сопротивление».

В тех редакциях, где задумываются о необходимости пополнить штат новыми специалистами для работы с цифровыми площадками, наблюдается тренд по сокращению заработных плат штатному персоналу новостной редакции: новые сотрудники с небольшим опытом работы стоят дешевле, а сотрудник со стажем «на старой более высокой зарплате держится за свое текущее место, а тем самым тормозит собственное развитие, потому что он понимает, чего от него хотят сейчас, и вряд ли он будет рисковать предлагать что-то новое» (Р1).

Однако не все сотрудники радиостанции готовы осваивать новые компетенции и приобретать навыки, связанные с работой на интернетплощадках: они по-прежнему уверены (Р8), что «эфирный новостник - это элита радийная. А писать новость на сайте это - дауншифтинг и вообще понижение». Поэтому на некоторых радиостанциях работа ведется довольно традиционно, а адаптация к новым технологиям идет медленно. Например, один топ-менеджер (Р9) поясняет, что его редакция новостей состоит из информационного ведущего и шеф-редактора, который следит за повесткой, отбирает поводы: он информационный управленец. Однако и в данном случае новые тенденции не обошли редакцию стороной: «идет объединение [функций] шефредактора телевизионного и радийного. Это будет один человек».

\section{Требования к профессиональным компетенциям}

Медиаменеджеры отмечают увеличение набора необходимых компетенций. Большинство редакций вместо создания новых мест, связанных с изменением журналистских специализаций, требуют освоения новых технологий от сотрудников редакции. Таким образом, журналист должен быть все более универсальным. Одни медиаменеджеры указывают на расширение профессиональных обязанностей: корреспондент должен «хотя бы на минимальном профессиональном уровне делать любую работу, включая съемку и монтаж видео, я уж молчу о монтаже звука, умении придумать вопросы гостю, спикеру, ну, и мало-мальски иметь какое-то чувство вкуса» (Р1).

Другие руководители уделяют внимание управлению контентом в 
социальных сетях, на веб-ресурсах: «все, что связано с превращением вашего контента в подкасты (в его производстве есть своя специфика) - в этих областях лежит компетенция людей, которые будут нужны и востребованы. ... Все, что касается продвижения радиостанции в онлайн среде, онлайн маркетинга - все это будет очень востребовано» (P7).

Сегодня и редактор, и корреспондент должны осваивать процесс всей цепочки производства контента. Так, по словам одного из топ-менеджеров (Р6), «редактор должен не только записать комментарий, взять интервью, порезать, смонтировать звук, но и сделать подводку к социальным сетям, выложить что-то туда (SMM), написать текст на сайт, а если надо, то еще и в газету. Плюс они должны уметь снять видео и отправить фрайл. Журналисты снимают видео на айфон (раньше мы покупали камеры, но сейчас от этого отказались). ... Для тех, кто работает в полях - для них у нас есть репортерская сумочка (радийный микрофон, диктофон, камера, ноутбук с сильными аккумуляторами). Фото мы можем купить в агентстве - не будем усложнять жизнь нашему корреспонденту. Но мы знаем, если что - наш корреспондент это сможет сделать». Однако говорить о том, что требование универсализации характерно для всех информационных радиостанциях, пока рано.

\section{Удаленная работа}

По отношению к удаленной работе радиоредакции довольно консервативны. Большинство топменеджеров негативно относится к подобной практике, порицая «уда- ленку» в своей редакции. Основной причиной является то, что радиовещание завязано на показатели качества звука и контента. Если текст и звук можно создать за пределами редакции, то, качество интервью, взятого вне студии, вряд ли будет достойным эфира федеральной радиостанции.

С журналистами и редакторами руководители работать удаленно не готовы, но есть опыт привлечения к дистанционной работе специалистов других профилей, например, модераторов сайта или дизайнеров (Р3).

Лишь один опрошенный топменеджер упомянул о том, что в редакции существует практика удаленной работы - технические возможности позволяют. Однако в приоритете для проведения интервью - студия, так как необходим «физический контакт», возможность смотреть человеку в глаза (Р10).

\section{Фриланс}

Отношение к фрилансу разное. Редакции склонны прибегать к привлечению фрилансеров только в случае крайней необходимости. Частные радиостанции чаще могут позволить себе подобную практику, нежели государственные.

Работа с фрилансерами в государственных компаниях связана со сложностью финансирования проектов («Это нужно закладывать в бюджет. А, как правило, такие темы возникают с бухты-барахты, и это сложно запланировать» (P1), «найти ресурс выстраивания сети этих народных корреспондентов сложно» (Р9)). У крупных государственных компаний, как правило, есть собственная сеть региональных журналистов, в редких случаях и фрилансеры, которые мо- 
гут подготовить репортаж с места и перебросить по Интернету» (P4, P9). Тут скорее речь идет об уникальной информации, «от которой никто не откажется» (P9).

Частные компании практикуют привлечение фрилансеров только в случае острой необходимости, объясняя это тем, что слушатель привыкает к знакомым голосам в эфире Фрилансеры в данном случае - люди, которые акцентируют внимание на том или ином событии (P10). Например, в одной из редакций используется система hackpack. press, где зарегистрированы и верифицированы журналисты со всего мира: «если нужен, допустим, журналист, находящийся в Таджикистане и наблюдающий за бунтом заключенных, я могу найти такого журналиста за пару минут, заплатить ему деньги через систему» (Р2).

\section{Взаимоотношение с коллегами}

Социальные сети превратились в привычный рабочий коммуникатор. Причем приоритетов при выборе социальной сети не существует: способ коммуникации выбирается самой редакцией в зависимости от удобства (чаще всего респонденты упоминали Facebook и Telegram). Одни редакции предпочитают функционал Telegram (P2, Р3), другие WhatsApp-чаты, также существуют отдельные корпоративные сетевые мессенджеры (P4). Практически все респонденты отметили, что чаты не только ускоряют принятие решений, но улучшают оперативность и прозрачность управления (Р10), а также облегчают общение (P5).

Некоторые топ-менеджеры убеждены, что планерки и другие очные совещания - «самый дорогой вид управления» (Р3) и «просто трата времени» (Р1). Большинство планерок проходит согласно традиции в редакции, но руководящий состав думает над переходом в новый формат. Например, серьезно вмешался в корпоративные процедуры Skype: «мы с некоторыми коллегами можем годами не видеться, но общаемся там чуть ли не еженедельно» (Р3). Возможно, обсуждение тем и проблем «за одним столом» станет реже, но не уйдет совсем. Сложность перехода на другой уровень заключается в том, что для некоторых сотрудников планерка - важная часть, «потому что: а) в диалоге решить и придумать проще, б) такая еще менеджерская штука важная, чтобы компания видела, что мы все вместе, а не каждый сам за себя» (P1).

\section{Мотивация}

Медиаменеджеры выделили несколько наиболее ярких мотиваторов для сотрудников редакций радиостанций: деньги, личные амбиции и интерес.

Что касается денег, то они не всегда выступают решающим фрактором - «важно иметь отношение именно к бренду, и это, в общем, практически часть вознаграждения - иметь отношение к популярной и влиятельной радиостанции, это достаточно круто» (Р3).

Другой мотивацией являются рейтинги ведущих, которые ведутся на радиостанциях: «если они видят какое-то снижение на протяжении нескольких недель, они начинают анализировать» (Р5). У редакторов своя мотивация: им важна реакция на их программу и похвала руководства» (P5). 
В одной из редакций есть гонорарный и премиальный фонд: на радиостанции невысокие оклады, но за счет работы и на радио, и на сайт, и на газету получается неплохая зарплата (Р6).

Во всех редакциях есть люди, у которых «горят глаза», они хотят качественно сделать свою работу и отличиться (Р8). Профессиональный уровень таких редакций такой, «к которому очень хочется приобщиться» (Р10), «где-то 5-я - 6-я часть людей, которым интересно, несмотря на возраст (Р1)».

Тем не менее, респонденты отмечают также тот фракт, что со временем мотивация сотрудников ослабевает, поддерживать энтузиазм довольно трудно: «есть те, кто уже давно в этой профессии и даже устали от журналистики» (P9), есть люди, которые пытаются приспособиться под обстоятельства и с трудом воспринимают любые изменения» (P1). В такой ситуации топ-менеджеры пытаются побудить журналистов к самосовершенствованию, иначе «ты не будешь нужен, потеряешь квалифрикацию» (P9).

\section{ЖУРНАЛИСТ / РЕДАКТОР}

\section{Сбор информации. Новое в работе.}

Развитие технологий оказало влияние на специфику сбора информации благодаря возможности быстрого получения ее в Интернете и доступности источников.

Практически все респонденты заявили, что сейчас добывать информацию стало гораздо легче. Именно цифровизация значительно облегчает процесс работы в редакциях: наряду с традиционными лен- тами новостных агентств и ключевыми сайтами, появилось очень много источников информации - социальные сети, блогеры (P6), официальные твиттер-аккаунты компаний, звезд, телеграм-каналы (Р2). То есть «упрощается прежде всего справочная часть: человек может в ту же секунду, не сходя с места, узнать ответы на какие-то вопросы, которые вам собираются задать, или подготовиться к интервью и т.д. [...] Сейчас все в смартфоне» (Р4).

Отношение к социальным сетям как к источнику информации тоже стало меняться. И в данном случае, по мнению одного из респондентов, основная задача заключается в выработке правил верификации, «чтобы не позволить, в том числе с помощью социальных сетей, манипулировать ни СМИ, ни при помощи СМИ общественным мнением» (P10).

Кроме того, эксперты отметили, что цифровизация и обилие источников помогает преодолеть пространственные рамки. Например, можно просмотреть «сегодняшний «Нью-Йорк Таймс» или все что угодно - послушать радио любое из любой точки мира и задать вопрос, попробовать даже задать вопрос через как бы социальную сеть разным людям, с которыми ты не знаком» (Р3).

«Спикер начитывает на телефон, тебе отправляет. Это очень упростило жизнь. Плюс сама связь, можно устанавливать связь с кем-то, кто в эфире. Skype, Telegram, все это позволяет лучшее качество звука вывозить в эфир, практически студийное. Это тоже очень заметно». (Р5)

Цифровизация изменила и специфику работы самого журналиста. Он превратился из специалиста, 
которого «кормят ноги», в офисного работника. Радийщики подстраиваются под спикера: «если он в роуминге и не хочет, чтобы ему звонили на телефон, - ОК. Если ему проще включить Skype, пообщаемся через Skyре». Спикер может начитать информацию на телефон и отправить в редакцию или прокомментировать событие по Skype (P5). Респонденты отмечают и улучшение качества звука: оно «практически студийное» (P5), «раньше для того, чтобы обеспечить качественный звук, человек должен был приезжать в студию. Сейчас мы можем выехать к нему и обеспечить такой же качественный звук. Или вообще никуда не выезжать, достаточно нашему собеседнику загрузить программу в свой смартфон» (P2); «наговорите нам по этому вопросу, пришлите файл в WhatsApp или Skype. Через секунды все есть. Мы этот звук чистим - и все готово» (Р9).

В то же время скорость распространения информации в цифровой среде усложняет для радиостанций оперативное получение эксклюзивной информации, превращая информационное вещание в FM-диапазоне во «вторичное» массмедиа. Один из респондентов (Р8) поясняет, что соцсети и телеграм-каналы усложнили работу, потому что любое ведомство или коммерческая компания все, что они хотят сообщить миру, передают через свои ресурсы. «Сделать так, чтобы они рассказали об этом именно тебе, довольно сложно. Это касается в первую очередь государственных ведомств, каких-то крупных компаний, получить нечто специально для тебя сейчас очень сложно. Bce переходят в форму общения по переписке, по телефону вообще не- возможно ничего получить, если это не какой-то живой человек, депутат Петров или какой-то артист, кому ты можешь позвонить и поговорить», говорит он.

\section{Форматы и жанры}

Медиаменеджеры сходятся во мнении, что новые жанры и форматы на данный момент в информационном радиовещании не нужны. Единственный тренд, который можно отметить - модификация типов подачи материалов в сторону уменьшения объема. Но чаще всего все новое - это хорошо забытое старое. Нормой стало сопровождение материалов на цифровой платформе.

Некоторые радиостанции под влиянием клипового мышления более сжато излагают темы, выкладывают более короткие треки (P9). По их мнению, «жизнь становится быстрее, люди хотят получать сразу все за максимально короткое время» (Р2).

Многие отмечают отсутствие новых жанров: «все, что есть - это изложение, сюжеты, комментарии» (P1), «отдельных редакторов жанры интересуют в последнюю очередь, но главным остается интервью» (P6), «новых жанров нет, и это проблема» (P8).

В основном получают развитие старые жанры, например, репортаж. «Не так давно на радио появилась специальная программа-радиорепортаж, это такой классический репортаж со звуками, голосами, записанный на месте, не по телефону из редакции. Мы выгоняем корреспондентов на улицы, чтобы они делали репортажи», - отмечает респондент (P4). 
По поводу подкастов мнения расходятся: один из респондентов уверен, что в России подкасты не получили развития и «по сути все жанры на разговорном радио они свелись к авторским шоу, построенным на интерактивах» (P8).

Сегодня лишь единицы работают с подкастами, видят перспективы освоения новых форматов в Интернете. Один из респондентов отмечает, что подкасты можно слушать в любом месте в любое время: «подкасты очень востребованы - все, что касается социально-политической тематики, криминальной, бизнес, образовательной тематики».

Причем в отдельных редакциях отдают предпочтения большому формату: «человеку интереснее включить и слушать, чем каждые пять минут переключаться... Большая форма, роман востребован больше, чем рассказ» (Р5). Респондент поясняет, что огромный текст в онлайне трудно прочитать: «тебе четыре фрразы - и забывается. А звук, он, что радийный, что цифровой, воспринимается одинаково. Пробки - это как раз наша история, мы любим пробки». (Р5)

\section{Взаимодействие с аудиторией}

В эпоху распространения социальных сетей каждая радиостанция выбирает свой путь взаимодействия с аудиторией. Кто-то считает, что формат All News не предполагает интерактива: «Мы с аудиторией не общаемся, это наша принципиальная позиция» (Р3). Данный тренд подтверждает и другой респондент, который говорит, что в редакции не успевают общаться с аудиторией, на новость в Facebook или «Вконтакте» «приходит десятки и сотни комментариев, в которые сложно вмешиваться: «у нас две задачи: людей информировать и давать эмоции. Мы только маты иногда удаляем, чтобы это как помойка не выглядела. В основном мы не вмешиваемся» (Р8). Однако такой позиции придерживаются не все информационные радиостанции. Для общения с аудиторией используются разные каналы коммуникации: мессенджеры, страницы в социальных сетях (помимо собственного сайта):

«Мессенджерами мы пользуемся, чтобы взаимодействовать с аудиторией, потому что они пишут в WhatsApp, тоже гораздо удобнее, чем смс строчить» (P5). «Мы слушаем нашу аудиторию везде и в эфирных сообщениях, и в социальных сетях, «Вконтакте», Instagram, на нашем сайте. В общении с ведущими в тех же социальных сетях. Поток очень большой и фидбек мы получаем громадный» (P5).

Впрочем, традиционный интерактив, наряду с сообщениями в соцсетях, остался на многих радиостанциях. Редакции не отказываются от общения со слушателями, используя прямой эфир (P4). А некоторые открывают новые возможности общения: «У нас появилось больше каналов взаимодействия с аудиторией. Тот же Youtube-канал. Youtube-трансляция - это еще один канал взаимодействия с аудиторией, еще один способ взаимодействия с аудиторией. В Youtube есть чат, в прямой эфир нам пишут. Мы всегда его используем, мы за интерактивность. Мы используем все возможности интерактивности, в том числе, в нашем классическом радиоэфрире» (Р10). 
Стоит отметить, что некоторые новостные радиостанции используют свои телеграмм-каналы для взаимодействия с другими СМИ: «Последние три месяца мы заметили, что многие СМИ начали ссылаться не на нас, как на радиостанцию, а стали ссылаться на телеграммканал наш. Мы видим прямо, кто на нас подписан. Ставим какую-то новость в телеграмм-канал, через 3-4 мин. на «Медузе» появляется в ее телеграмм-канале репост или просто скопировали, вставили со ссылкой на нас. И мы в этом смысле тоже сместили акцент» (Р8).

\section{Выводы}

Медиаменеджеры, говоря о возможных изменениях на радиорынке, сходятся во мнении, что в ближайшие несколько лет радикальных изменений не предвидится: FMдиапазон сохранит свой приоритет в вещании.

Проявляющуюся, но не всегда осознаваемую многозадачность можно считать одной из важных современных особенностей работы сотрудников новостных редакций, во многом определяемых развитием технологий. Причем это связано не с воплощением в профессиональной реальности моделей так называемых универсальных журналистов (производителей разных типов контента текстов, фрото, видео, графики - в одном лице), а с развитием ситуации, когда при помощи компьютеров или мобильных устройств журналист в редакции совмещает, например, работу над текстом, просмотр соцсетей и отправку сообщений в мессенджерах, и не всегда идентифицирует их как разные производственные процессы. Важно заметить, что в последние годы социальные сети стали привычным рабочим коммуникатором, где можно не только почерпнуть важную информацию и разместить свою, но и площадкой для общения с экспертами, на которой это общение гораздо быстрее и порой эффективнее, чем встреча на мероприятии или разговор по телефону.

Развитие технологий влияет и на специфику производимого журналистом контента. В частности, преимущественно офисная работа влияет не только на то, как радиожурналисты коммуницируют с источниками и ищут темы, но и на то, какие типы материалов они в итоге производят. Полагаем, что сохраняющуюся привязанность к офису, которая оказывается выше, чем у иных креативных профессий, например, программистов или дизайнеров, можно объяснить необходимостью работы не над одним заданием, а над множеством материалов в течение дня; при этом журналист нуждается в постоянной коммуникации с редактором и доступе к широкому кругу технических средств.

\section{СПИСОК ИСПОЛЬЗОВАННОЙ ЛИТЕРАТУРЫ}

1. Boczkowski P.J. The Processes of Adopting Multimedia and Interactivity in Three Online Newsrooms / P.J. Boczkowski // Journal of Communication. — 2004. — Vol. 54, no. 2. P. 197-213.

2. Machill M. The Importance of the Internet for Journalistic Research / M. Machill, M. Beiler // Journalism Studies. - 2009. - Vol. 10, no. 2. - P. 178-203.

3. Reich Z. New Technologies, Old Practices: the Conservative Revolution in Communication Between Reporters and News Sources in the Israeli Press / Z. Reich // Journalism \& Mass Communication Quarterly. - 2005. - Vol. 82, no. 3. - P. 552-570. 
4. Reich Z. The Impact of Technology on News Reporting: a Longitudinal Perspective / Z. Reich // Journalism \& Mass Communication Quarterly. - 2013. - Vol. 90, no. 3. P. 417-434.

5. Dunaway J. What Predicts the Game Frame? Media Ownership, Electoral Context, and Campaign News / J. Dunaway, R.G. Lawrence // Political Communication. — 2015. Vol. 32, no. 1. - P. 43-60.

6. Fu W. Applying the Structure-Conduct-Performance Framework in the Media Industry Analysis / W. Fu // International Journal on Media Management. — 2003. — Vol. 5, no. 4. P. 275-284.

7. Yang J. Competing with Whom? Where? and Why (Not)? an Empirical Study of U.S. Online Newspapers' Competition Dynamics / J. Yang, I.C. Hsiang // Journal of Media Business Studies. - 2011. - Vol. 8, no. 4. - P. 59-74.

8. Litman B. The Television Networks, Competition and Program Diversity / B. Litman // Journal of Broadcasting. - 1979. - No. 23. - P. 393-409.

9. Häckner J. Advertising and Media Market Concentration / J. Häckner, S. Nyberg // Journal of Media Economics. - 2008. - Vol. 21, no. 2. - P. 79-96.

10. Ramstad G.O. A Model for Structural Analysis of the Media Market / G.O. Ramstad // Journal of Media Economics. - 1997. - Vol. 10, no. 3. - P. 45-50.

11. Lee A.M. The Rise of Online News Aggregators: Consumption and Competition / A.M. Lee, H.I. Chyi // International Journal on Media Management. - 2015. - Vol. 17, no. 1. - P. 3-24.

12. Лукина М.М. СМИ в пространстве Интернета / М.М. Лукина, И.Д. Фомичева. Москва : Изд-во МГУ, 2005. - 87 с.

13. Интернет-СМИ: теория и практика / под ред. М.М. Лукиной. - Москва : Аспект пресс, 2013. - 348 с.

14. Как новые медиа изменили журналистику. 2012-2016 / А. Амзин, А. Галустян, В. Гатов [и др.]. - Екатеринбург : Изд-во Гуманитар. ун-та, 2016. - 303 с.

15. Баранова Е.А. Конвергентная журналистика. Теория и практика : учеб. пособие / Е.А. Баранова. - Москва : Юрайт, 2014. - 269 с.

16. Каллиома Л.А. Адаптация как стадия перехода редакции к конвергентным основам информационного производства (опыт «Российской газеты») / Л.А. Каллиома // Медиаскоп. - 2013. — № 4. — URL: http://www.mediascope.ru/node/1434.

17. Индустрия российских медиа: цифровое будущее / Е.Л. Вартанова, А.В. Вырковский, М.И. Макеенко, С.С. Смирнов. - Москва : МедиаМир, 2017. - 160 с.

18. Вырковский А.В. Редакционный менеджмент в печатных и онлайновых массмедиа: процессный подход / А.В. Вырковский. - Москва : МедиаМир, 2016. - 384 с.

19. Вырковский А.В. Структура редакций СМИ: традиция и современность / А.В. Вырковский // Вестник Московского университета. Серия 10: Журналистика. 2017. — № 4. - C. 136-150.

20. Zotto C.D. Human resource leadership in highly dynamic environments: Theoretically based analyses of 3 publishing companies / C.D. Zotto // Journal of Media Business Studies. - 2005. - Vol. 2, no. 1. - P. 51-70.

21. Killebrew K.C. Culture, Creativity and Convergence: Managing Journalists in a Changing Information Workplace / K.C. Killebrew // International Journal on Media Management. - 2003. - Vol. 5, no. 1. - P. 39-46.

22. Lund M.K. More News for Less / M.K. Lund // Journalism Practice. — 2012. — Vol. 6 , no. 2. - P. 201-216.

23. Kung L. Strategic Management in the Media: from Theory to Practice / L. Kung. London : Sage Publications, 2008. - 237 p.

24. Picard R.G. Environmental and Market Changes Driving Strategic Planning in Media Firms / R.G. Picard // Strategic Responses to Media Market Change. - Jonkoping : International Business School, 2004. - P. 1-18.

25. Oliver J.J. Winning in High Velocity Markets: the Case of BskyB / J.J. Oliver // Strategic Direction. - 2012. - Vol. 28, no. 10. - P. 3-5. 
26. Oliver J.J. Media Management Tools: UK Broadcast Media Executives' Perspective / J.J. Oliver. — DOI10.108014241277.2013.863100 // International Journal on Media Management. - 2013. - Vol. 15, no. 4. - P. 245-257.

27. Сидорова О. Интернет-журналистика: адаптация к меняющейся реальности / O. Сидорова, М. Корнев, С. Паранько // Медиапроекты Mail.ru. — URL: https://media.mail. ru/\#about.

28. Luscombe A. Radio Journalists and how they Describe their Written Copy / A. Luscombe // Journal of Media Practice. - 2009. - Vol. 10, no. 1. - P. 5-15.

\section{REFERENCES}

1. Boczkowski P.J. The Processes of Adopting Multimedia and Interactivity in Three Online Newsrooms. Journal of Communication, 2004, vol. 54, no. 2, pp. 197-213.

2. Machill M., Beiler M. The Importance of the Internet for Journalistic Research. Journalism Studies, 2009, vol. 10, no. 2, pp. 178-203.

3. Reich Z. New Technologies, Old Practices: the Conservative Revolution in Communication Between Reporters and News Sources in the Israeli Press. Journalism \& Mass Communication Quarterly, 2005, vol. 82, no. 3, pp. 552-570.

4. Reich Z. The Impact of Technology on News Reporting: a Longitudinal Perspective. Journalism \& Mass Communication Quarterly, 2013, vol. 90, no. 3, pp. 417-434.

5. Dunaway J., Lawrence R.G. What Predicts the Game Frame? Media Ownership, Electoral Context, and Campaign News. Political Communication, 2015, vol. 32, no. 1, pp. 43-60.

6. Fu W. Applying the Structure-Conduct-Performance Framework in the Media Industry Analysis. International Journal on Media Management, 2003, vol. 5, no. 4, pp. 275-284.

7. Yang. J., Hsiang I.C. Competing with Whom? Where? and Why (Not)? an Empirical Study of U.S. Online Newspapers' Competition Dynamics. Journal of Media Business Studies, 2011, vol. 8, no. 4, pp. 59-74.

8. Litman B. The Television Networks, Competition and Program Diversity. Journal of Broadcasting, 1979, no. 23, pp. 393-409.

9. Häckner J., Nyberg S. Advertising and Media Market Concentration. Journal of Media Economics, 2008, vol. 21, no. 2, pp. 79-96.

10. Ramstad G.O. A Model for Structural Analysis of the Media Market. Journal of Media Economics, 1997, vol. 10, no. 3, pp. 45-50.

11. Lee A.M., Chyi H.I. The Rise of Online News Aggregators: Consumption and Competition. International Journal on Media Management, 2015, vol. 17, no. 1, pp. 3-24.

12. Lukina M.M., Fomicheva I.D. SMI v prostranstve Interneta [Media in the Internet Space]. Lomonosov Moscow State University Publ., 2005. 87 p.

13. Lukina M.M. (ed.). Internet-SMI: teoriya i praktika [Internet Media: Theory and Practices]. Moscow, Aspekt press Publ., 2013. 348 p.

14. Amzin A.A., Galustyan A., Gatov V., Kastels M., Kulchitskaya D. Kak novye media izmenili zhurnalistiku. 2012-2016 [How New Media Has Changed Journalism. 2012-2016]. Ekaterinburg, The Liberal Arts University Publ., 2016. 303 p.

15. Baranova E.A. Konvergentnaya zhurnalistika. Teoriya i praktika [Convergent Journalism. Theory and Practices]. Moscow, Yurait Publ., 2014. 269 p.

16. Kallioma L.A. Adaptation as a Stage of Newsroom Transformation to Convergent Basics of Information Production (Case Study of "Rossiyskaya Gazeta"). Mediaskop = Mediascope, 2013, no. 4. Available at: http://www.mediascope.ru/node/1434. (In Russian).

17. Vartanova E.L., Vyrkovsky A.V., Makeenko M.I. Smirnov S.S. Industriya rossiiskikh media: tsifrovoe budushchee [Industry in the Russian Media: the Future is Digital]. Moscow, MediaMir Publ., 2017. 160 p.

18. Vyrkovsky A.V. Redaktsionnyi menedzhment v pechatnykh i onlainovykh massmedia: protsessnyi podkhod [Editorship Management in Printed and Online Media: a Process Approach]. Moscow, MediaMir Publ., 2016. 384 p.

19. Vyrkovsky A.V. The Editorial Structure of Mass Media: Tradition and Modernity. Vestnik Moskovskogo universiteta. Seriya 10: Zhurnalistika = Moscow University Journalism Bulletin, 2017, no. 4, pp. 136-150. (In Russian). 
20. Zotto C.D. Human Resource Leadership in Highly Dynamic Environments: Theoretically Based Analyses of 3 Publishing Companies. Journal of Media Business Studies, 2005, vol. 2, no. 1, pp. 51-70.

21. Killebrew K.C. Culture, Creativity and Convergence: Managing Journalists in a Changing Information Workplace. International Journal on Media Management, 2003, vol. 5, no. 1 , pp 39-46.

22. Lund M.K. More News for Less. Journalism Practice, 2012, vol. 6, no. 2, pp. 201-216.

23. Kung L. Strategic Management in the Media: from Theory to Practice. London, Sage Publications, 2008. 237 p.

24. Picard R.G. Environmental and Market Changes Driving Strategic Planning in Media Firms. In Picard R.G. (ed.). Strategic Responses to Media Market Change. Jonkoping International Business School, 2004, pp. 1-18.

25. Oliver J.J. Winning in High Velocity Markets: the Case of BskyB. Strategic Direction, 2012, vol. 28 , no. 10 , pp. 3-5.

26. Oliver J.J. Media Management Tools: UK Broadcast Media Executives' Perspective. International Journal on Media Management, 2013, vol. 15, no. 4, pp. 245-257. DOI:10.1080 14241277.2013.863100.

27. Sidorova O., Kornev M., Paranko S. Online Journalism: Adapting to a Changing Reality. Media Project Mail.ru. Available at: https://media.mail.ru/\#about.

28. Luscombe A. Radio Journalists and how they Describe their Written Copy. Journal of Media Practice, 2009, vol. 10, no. 1, pp. 5-15.

\section{ДЛЯ ЦИТИРОВАНИЯ}

Трансформация работы сотрудников информационных радиостанций в условиях цифровизации / А.В. Вырковский, А.В. Колесниченко, А.Ю. Образцова, М.Ю. Галкина, С.C. Смирнов, М.Б. Владимирова, И.Д. Фомичева. - DOI: 10.17150/23086203.2020.9(3).443-461 // Вопросы теории и практики журналистики. - 2020. - Т. 9 , № 3. - C. 443-461.

\section{FOR CITATION}

Vyrkovsky A.V., Kolesnichenko A.V., Obraztsova A. Yu., Galkina M. Yu., Smirnov S.S., Vladimirova M.B., Fomichyova I.D. Changes in News Radio Editors' Work in the Context of Digitalization. Voprosy teorii $i$ praktiki zhurnalistiki $=$ Theoretical and Practical Issues of Journalism, 2020, vol. 9, no. 3, pp. 443-461. DOI: 10.17150/2308-6203.2020.9(3).443-461. (In Russian). 